\title{
Spatial Characteristics of Traditional Villages under the Influence of Religious Beliefs: The Case of Datun Village, China
}

\author{
Gegentana, Longge Di, Tinghua Hu, Xiaoqing Hu, Yuanjing Yin \\ Southwest National University, Chengdu, China \\ Email: 328515017@qq.com
}

How to cite this paper: Gegentana, Di, L. G., Hu, T. H., Hu, X. Q., \& Yin, Y. J. (2020). Spatial Characteristics of Traditional Villages under the Influence of Religious Beliefs: The Case of Datun Village, China. Current Urban Studies, 8, 156-165. https://doi.org/10.4236/cus.2020.82008

Received: March 27, 2020

Accepted: April 12, 2020

Published: April 15, 2020

Copyright () 2020 by author(s) and Scientific Research Publishing Inc. This work is licensed under the Creative Commons Attribution International License (CC BY 4.0).

http://creativecommons.org/licenses/by/4.0/

\begin{abstract}
As the carrier of thousands of years of farming culture in China, the value of traditional villages is self-evident, with the rapid development of cities, the problem of hollowing out villages is becoming more and more serious, and religious traditional villages are rich in culture and are also facing threats. Taking Datun village with strong religious belief and well-preserved spatial features of the village as an example, starting from the religious belief of the traditional village, through the information consultation and field research, the influence of religion and belief on the spatial structure, street structure and public space structure of the traditional village is discussed, and the investigation and research provide the foundation for the renewal and development of the research and development of the traditional village of religion in our country.
\end{abstract}

\section{Keywords}

Religion and Belief, Traditional Villages, Spatial Patterns

\section{Introduction}

\subsection{Purpose and Meaning of Research}

Traditional villages have their regional value according to their different geographical environment, natural resources and cultural heritage of different genealogy families, and with the increasing lying of villages with the outside world, the problem of hollowing out villages is becoming more and more serious, and the cultural heritage of traditional villages is under threat (Guo, 2018). Religious belief takes space as the carrier, is a special ideological and cultural phenomenon, the development of traditional villages by the influence and restriction of 
religious belief culture.

Through the investigation and analysis of Datun Village, this study tries to explore the influence of religious belief on the spatial characteristics of traditional villages from the perspective of religious belief, and provides a theoretical basis for the protection and utilization, construction and innovation of the spatial characteristics of traditional religious villages in the new period, so that the traditional villages can not only meet the material needs, but also be able to build under the guidance of cultural characteristics.

\subsection{The Current Situation of Research at Home and Abroad}

Domestic research on traditional villages is the earliest from the traditional architecture research, with the development of urbanization, the more popular local culture is people, the study of traditional villages is not limited to this. At present, the research on religious villages is reflected in the cultural tradition of national religion, as well as the influence of religion on the production and living space pattern and social relations of the surrounding villages, many scholars have made great exploration and research on the relationship between religion and village, and inferred from their spatial form and evolutionary mechanism.

Through combing, it is found that the research content of the protection of historical and cultural towns and villages in foreign countries mainly focuses on the protection and restoration of local buildings, the idea of protection of traditional villages, the tourism development of traditional villages and so on. Research centers in various countries tend to favour urban development, and the study of villages is also neglected, with relatively few research results (Cao, Cao, \& Yang, 2018).

At present, the vast majority of scholars in the past from the perspective of ethnology, religion and political science, less from the perspective of planning. This paper takes this as a starting point to explore the influence of religious belief on the spatial characteristics of traditional villages and provide a theoretical basis for the protection and development of traditional villages.

\section{Traditional Village Survey and Analysis}

\subsection{Research Content}

Taking Datun village as the research object, through the method of literature review and field visit research, this paper studies the spatial characteristics of religion and belief from the three aspects of the village's spatial structure, street structure and public space structure, and analyzes and organizes the information, which provides the foundation for the renewal, transformation and development of the traditional village research.

\subsection{Village Overview}

Datun Village is located in Songpan County, Aba Tibetan Autonomous Prefec- 
ture, Sichuan Province, ten-mile Hui township, along the Linyu River, and the National Road 213 line across the river. The village is the main temple town in the north, the village of Yousuotun to the south, the village of Gaotunzi in the west, and the village of Dazhai to the east. Village site selection is focused on back mountain water, Datun village according to favorable terrain to build houses, close to the river, 213 National Road, forming a "concentrated group" of the spatial pattern (Figure 1).

\subsection{Religious Beliefs and Religious Patterns in Villages}

In Datun village, the most important resident villagers are Hui and Han, the religion of the Hui faith is Islam, the Han people believe in Buddhism, and there are mosques and Buddhist monasteries in the village. Datun village by the influence of religious belief, built a different size of temples, there are mosques, five fairy temples, Guanyin temple, quartet temple, etc., the space layout around the temple, and finally in the space to form a temple-centered grid-shaped irregular village.

The distribution of temples has an important influence on the overall form of the village, Datun village belongs to the "one village number of temples" form, from the overall spatial layout of Datun village, Buddhist temples are located in the village, along with the axis distribution, forming a clear religious axis (Figure 2). The terrain is low to high, with different Buddhist temples, namely the Quartet Temple, the Five Fairy Temple, the Guanyin Temple and the Mamma Temple. Among them, the Four Temples and The Wuxian Temple sit in the center of the village, the old age, the Guanyin Temple is located on the hillside behind the village, is the villagers to protect the forest on the old mountain and built later, the terrain is higher, the mother temple is located on the top of the mountain, play an iconic role.

The temple pattern in Datun village is not big, in the spatial layout will not be

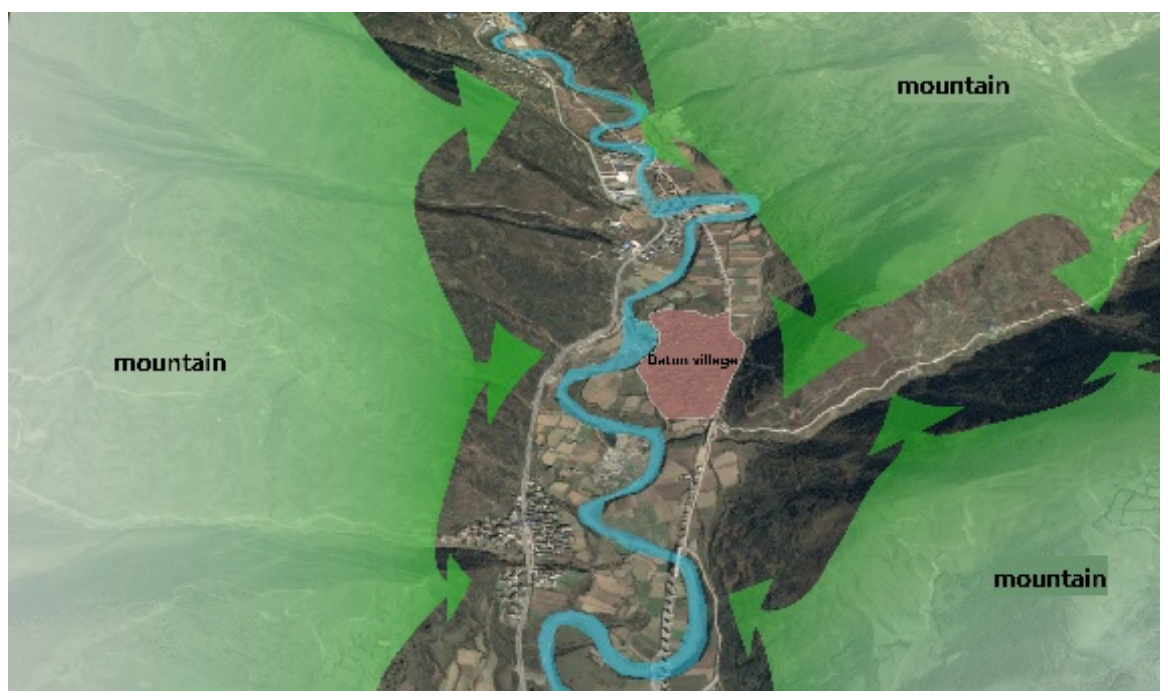

Figure 1. Datun village landscape pattern (Picture source: author's self-portrait). 


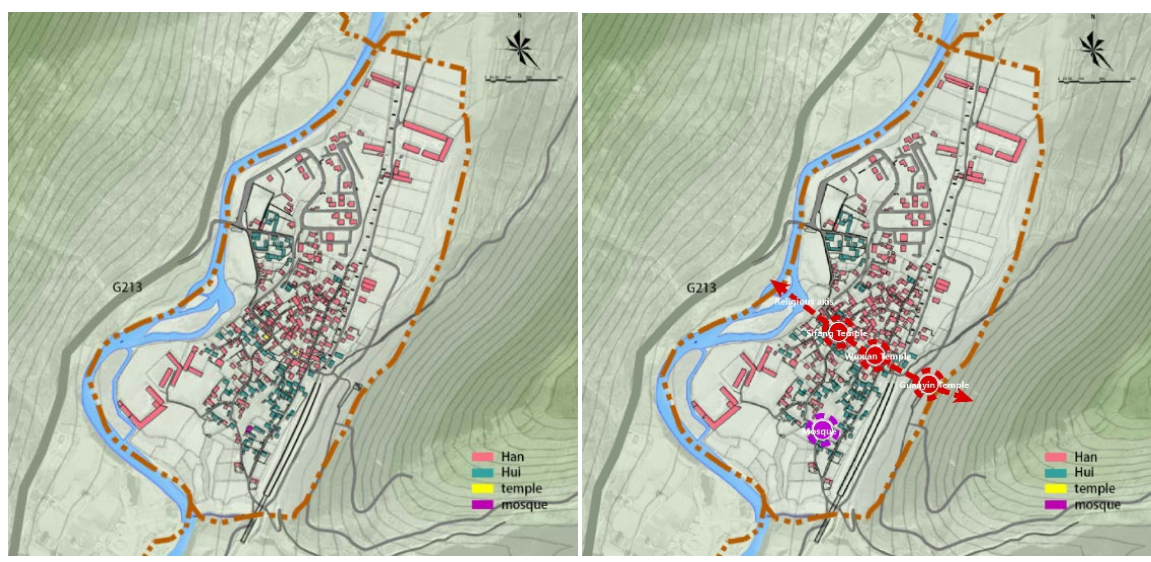

Figure 2. Chart of religious belief patterns in Datun village (Picture source: author's self-portrait).

graded, more into the life of the villagers, residents more "around the temple and live", in the village to form a gathering point, but the various temples in the layout of the formation of axis, become the center of the village, the whole village closely linked, the village is actually a potential belief culture.

The mosque is located on the outskirts of the village, distributed in the south, in a relatively independent location for individual construction, so that the temple in front of a more open space, can obtain a wider public space, Hui residents live around the temple, belong to the spontaneous residence of the mosque as the center of the circle around a circle of circular space scattered in a mesh structure.

\section{The Role and Influence of Religion on the Spatial Pattern of Villages}

\subsection{Relationship between Religion and Village Spirit}

\subsubsection{The Aspiration of the Villagers}

In the initial stage of the village's beginning to form, the overall spatial layout of the village takes on the characteristics of heart orientation. The so-called cententism refers to the village with a spiritual center, the villagers are close to this center, he stressed a subjective psychological state, with social character. In addition to the function of sacrifice, most of the monasteries in the village are responsible for the function of public activities, public places through activities to bring the villagers together, creating a human connection, to meet the spiritual needs of the villagers, enhance the villagers' sense of belonging and embodies the cohesion and dedication of the village's religious belief culture.

\subsubsection{The Cultural Nature of the Village}

The monastery bears the spiritual core and cultural function in the village, which provides space for the development of public activities, such as folk cultural performances with local characteristics, sacrifices and other activities, which enrich the spiritual and cultural life of the villagers. Religion Faith transforms 
from intangible to tangible through the organization of activities, which is also a way of cultural heritage.

\subsection{Relationship between Religion and Village Spatial Structure}

\subsubsection{Surrounded by Temple}

The Mosque in The Village of Datun is located in the south of the village, and the mosque is not located in the center of the settlement, but the pattern of the residence around the layout of the mosque is clearly visible. Muslims all over the world worship towards Meccaker White, so the church in the village of Datun is facing the west to the east.

\subsubsection{Circular Structure}

Residents around the layout of the mosque, with the mosque as the center of the circle unfolded (Figure 3), living around the mosque are the same family, the village of important public space or the village has prestige family close to the mosque.

\subsubsection{By the Mountains and Waters}

Hui settlement is built in the water, water for Islam is the existence of supreme purity, the location of the village and the water demand has a close relationship. Back mountain surface water, conducive to the defense, but also for the development of agriculture in the village provides a convenient condition.

\subsection{Relationship between Religion and Village Street Pattern}

Mosques have had an impact on the form of roads in the village of Datun, where roads should lead to mosques, so that villagers can participate in religious activities. The main road in the village is centered on a mosque or its square, spreading to the surrounding population, with a small radiographic road (Figure 4). Intersections exist in the form of T-shaped (Table 1), in order to ensure that the villagers have a quiet living and sacrificial environment, the road is in a T-shaped shape, with the characteristics of communication and poor, conducive to reducing external interference, while the characteristics of winding twists and
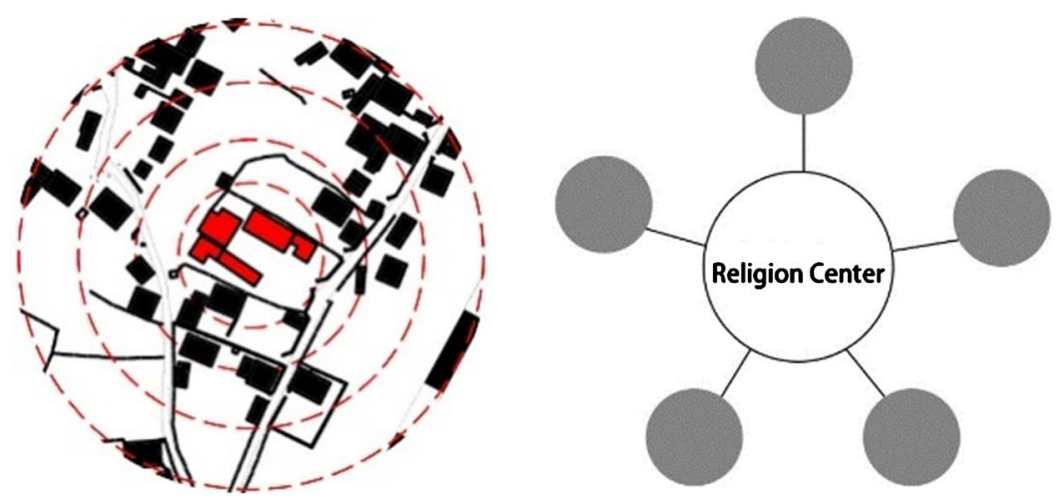

Figure 3. Structure of the Mosque in the village of Datun (Picture source: author's selfPortrait). 


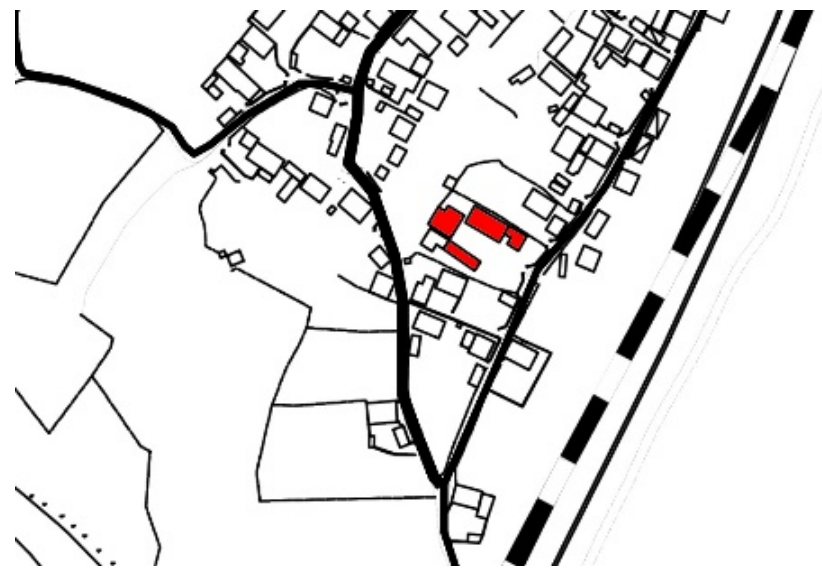

Figure 4. The main roads in the mosque and the village (Picture source: author's selfportrait).

Table 1. Analysis of the spatial pattern of streets and alleys (Table source: author's selfportrait).

Organization pattern type

turns are conducive to weakening The impact of the wind environment.

\subsection{Relationship between Religion and Village Public Space}

As the most important public space of Hui village, Datun Village will be the square and the mosque combined set up, some sacrificial activities can be carried out by the mosque in front of the site, such as Eid al-Fitr, Gulbon, Holy Chronicle, etc., these activities need to be borne by a certain amount of space, and these social exchanges have the openness, publicity and secularity to make it the most characteristic public space (Figure 5 ). 


\section{The Effect of Folk Belief on the Spatial Pattern of Villages}

\subsection{Relationship between Folk Belief and Village Space Layout}

\subsubsection{Location of the Temple}

Temple buildings are closely related to the village, and the location of the temple is located near or within the village (Bai, 2014). There are three Buddhist temples inside the temple in The Village of Datun, which is distributed by axis and a temple on the outside hill, which acts as a symbol.

\subsubsection{The Impact of Temples on Residential Buildings}

The layout and orientation of residential buildings are affected by the temple. In the layout of the building, the layout of the residential buildings presents a dense feature, the density of residential buildings around the temple is higher than the density of the other areas of the village, and the temple surrounding the residence and the temple will be separated, the temple will be surrounded by a piece of open space, If there is not enough space, a road may be left as a partition, mainly for the daily public gathering in the village to leave a space (Wang, 2019).

In the building orientation, the buildings around the temple are generally the same as the orientation of the temple, while in other areas of the village, the orientation of the building is freer (Figure 6).

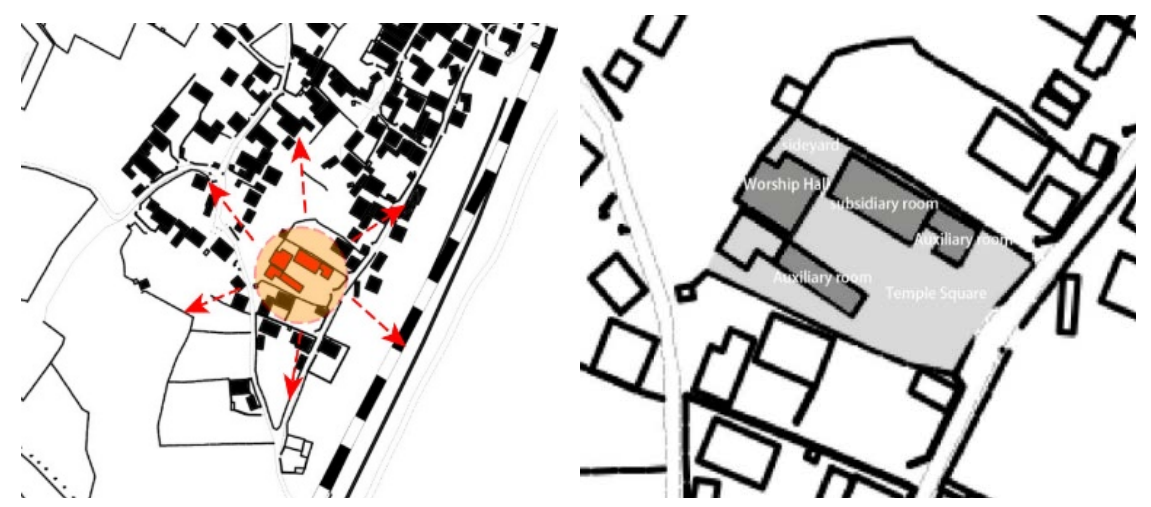

Figure 5. Analysis of the spatial pattern of mosques. (Picture source: author's self-portrait).

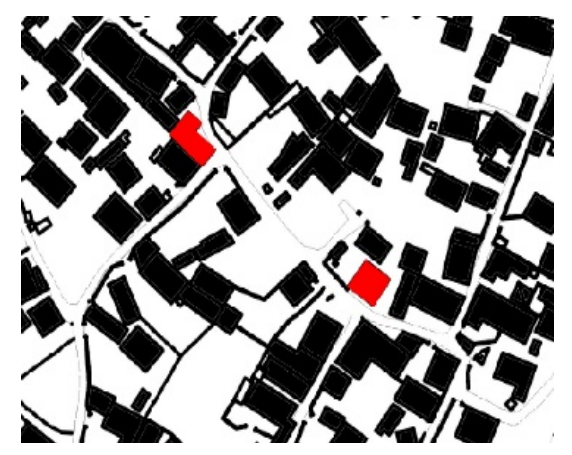

(a)

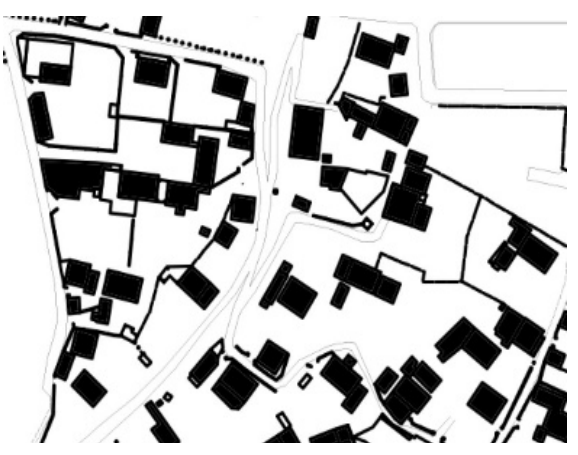

(b)

Figure 6. (a) Temple sits surrounding building density and direction; (b) Other building density and orientation. (Picture source: author's self-portrait). 


\subsection{Relationship between Folk Belief and Village Street Pattern}

1) The constituent elements of village streets and alleys

The streets and alleys of Datun Village contain two levels of street and alley. Temples are often built in conjunction with streets to facilitate the holding of ceremonies and events by villagers (Figure 7).

2) The function and distribution characteristics of village streets and alleys

The temples in The Village of Datun are located on the main road. From the point of view of street density, the density of streets around the temple is higher than that of the other areas of the village, and the accessibility of the temple is also higher, making it easier for the villagers to pass. At the same time, temples are attached to this random appearance due to the demand for sacrifice (Figure 8).

3) The structural relationship between village streets and alleys

Since the temple in Datun Village is located on the main axis inside the village, the streets of the village present a launch-style layout structure, the axis where the temple is located is the main street of the village, and the whole village's street structure consists of the main street and the extended laneway (Figure 9).

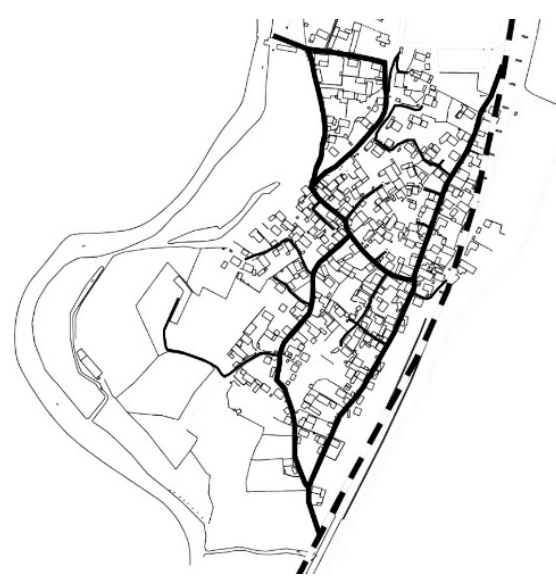

(a)

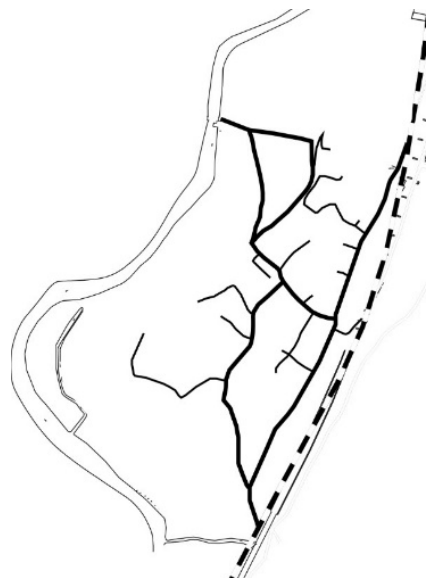

(b)

Figure 7. The spatial structure of streets and alleys. (Picture source: author's self-portrait).

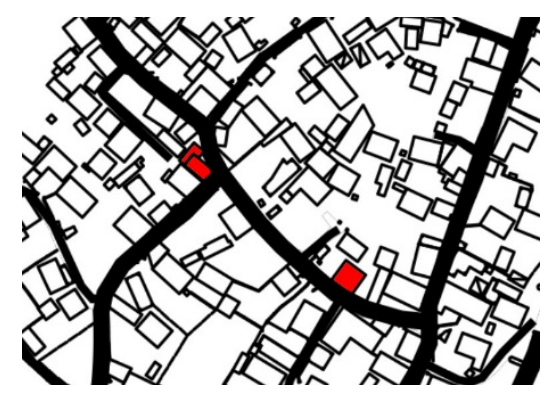

(a)

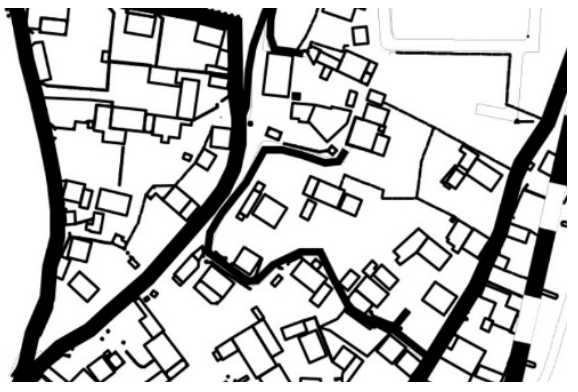

(b)

Figure 8. (a) Density of streets and alleys around the temple; (b) Other street density. (Picture source: author's self-portrait). 


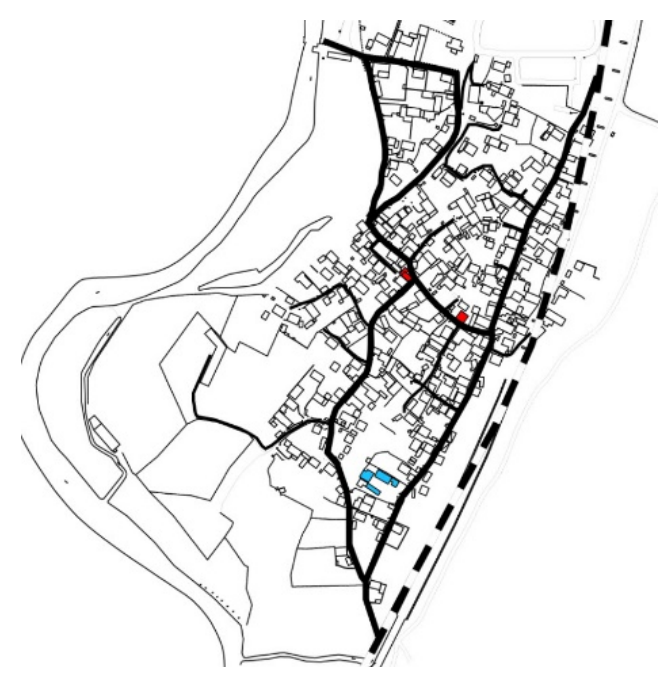

Figure 9. Launch layout of street structure (Picture source: author's self-portrait).

\subsection{Relationship between Folk Belief and Village Public Space}

1) Temples are the elements and characteristics of the public space of traditional villages

The various cultural activities and sacrificial activities in the village are carried out mostly through the space of the temple or its former square, mainly in the village of Datun.

People and God are connected through the sacrificial activities of believers, which require space as a carrier, and these public spaces became the most human in the village because of their inclusiveness, diversity and openness. A space with characteristics.

2) The influence of temples on the public space of traditional villages

The three Buddhist temples in Datun village together constitute the village's folk belief system, and many small temples are formed from the different needs of people, and getting rich, begging for sons and rains is the most desired in the hearts of villagers, and a number of smaller gathering sites have been produced around each temple.

\section{Conclusion}

The value of traditional villages is self-evident, for the study of traditional villages, not only at the material level, but also should pay attention to the cultural attributes of traditional villages, religious beliefs for the traditional village research provides a unique perspective, this kind of research for the protection and development of village culture has a unique value and significance.

Through the study of the influence of religious belief on the spatial characteristics of traditional villages, this paper finds that the temple, as the spiritual and cultural center of the village, has an influence on the spatial structure of the village, the street structure and the public space structure, and it is necessary for us to provide a theoretical basis for the protection and development of the tradi- 
tional village through the study and reflection of the spatial characteristics of the religious belief culture and the traditional village.

\section{Conflicts of Interest}

The authors declare no conflicts of interest regarding the publication of this paper.

\section{References}

Bai, P. F. (2014). A Study on the Cultural Space of Belief in Traditional Villages in Central Shanxi. Xi'an: Xi'an University of Architecture and Technology.

Cao, L., Cao, M. Y., \& Yang, Y. (2018). An Overview of the Research on the Protection and Development Planning of Traditional Villages in China. Chizhou College Journal, 32, 22-28.

Guo, M. (2018). Study on the Protection and Development of Traditional Villages in Luliang Mountain under the Strategy of Rural Revitalization. Xi'an: Xi'an University of Architecture and Technology.

Wang, L. (2019). A Study on the Spatial Pattern of Traditional Villages in Central Henan under the Influence of Folk Belief Culture. Zhengzhou: Zhengzhou University. 